\title{
Counseling patients with higher-risk MDS regarding survival with azacitidine therapy: are we using realistic estimates?
}

\author{
Amer M. Zeidan ${ }^{1,2}$, Maximilian Stahl ${ }^{1,2}$, Michelle DeVeaux ${ }^{3}$, Smith Giri ${ }^{1,2}$, Scott Huntington ${ }^{1,2}$, Nikolai Podoltsev $\mathbb{B}^{1,2}$, \\ Rong Wang ${ }^{2,4}$, Xiaomei Ma ${ }^{2,4}$, Amy J. Davidoff, ${ }^{2,5}$ and Steven D. Gore
}

Azacitidine is the only drug proven to prolong overall survival (OS) in patients with higher-risk myelodysplastic syndromes (HR-MDS) in the large randomized trial AZA001 with a median OS of 24.5 months among azacitidinetreated patients vs. 15.0 months in the conventional care regimens $(\mathrm{CCR})$ arm, with a hazard ratio of $0.58 ; p=$ $0.0001^{1}$. Two-year OS probability was $51 \%$ in azacitidine arm compared with $26 \%$ in the CCR arm $(p<0.0001)$. These numbers are often quoted to counsel HR-MDS patients regarding expected benefits with azacitidine therapy.

However, several real-life data and registry studies suggest that the median OS benefit with azacitidine is much lower (a median of 13-16 months) than what is suggested by AZA-001 trial $^{2-8}$. Additionally, in a recent large Surveillance, Epidemiology, and End Results (SEER)-Medicare-linked database study of 532 patients with refractory anemia and excessive blasts (RAEB), the median OS was found to be only 11 months [95\% confidence interval (CI), 10-14 months] for azacitidine treated patients in the United States (US) ${ }^{9}$. Furthermore, comparing OS for all patients with MDS before the approval of azacitidine and decitabine (2001-2003) and after their approval (2007-2010) using SEER Medicare data shows that the OS for MDS patients has not improved substantially after the approval of the two hypomethylating agents azacitidine and decitabine in 2004 and 2006, respectively, in the $\mathrm{US}^{10}$. When analysis was restricted to patients with RAEB, a proxy for HR-MDS, an improvement in OS of only

\footnotetext{
Correspondence: Amer M. Zeidan (amer.zeidan@yale.edu)

${ }^{1}$ Yale University and Yale Cancer Center, New Haven, CT, USA

${ }^{2}$ Yale Cancer Outcomes Public Policy, and Effectiveness Research (COPPER)

Center, New Haven, CT, USA

Full list of author information is available at the end of the article
}

3 months was observed, which is quite small compared with the initial survival advantage of 9.5 months reported in the AZA-001 trial. Similarly, an analysis of 1000 MDS patients at the Mayo Clinic showed that OS has not significantly improved for patients with MDS over the last two decades ${ }^{8}$.

Certainly, the marked difference in median OS between the AZA-001 trial and real-life analyses can be attributed to many factors including the stricter selection of patients in clinical trials compared to registry studies, which often include older and frail patients. To get a more realistic estimate of OS with azacitidine and minimize the effect of selection bias when comparing clinical trial data with reallife data, we pooled OS data from these clinical trials including the landmark AZA-001 trial. First, we conducted a literature search for published prospective clinical trials that had an azacitidine monotherapy arm at the standard approved dose $\left(75 \mathrm{mg} / \mathrm{m}^{2} /\right.$ day for 7 days $)$ in which OS results were presented in Kaplan-Meier (KM) methodology. Next, we used GetData Graph Digitizer Version 2.26 to digitize the published KM curves of the azacitidine monotherapy arms in these trials. An algorithm developed by Guyot et al. was implemented in the $\mathrm{R}$ statistical software to recreate individual patient level data based on the information from each KM curve, number of patients at risk, and number of events ${ }^{11}$. Individual patient level data were pooled for patients receiving azacitidine to produce overall $\mathrm{KM}$ estimates and estimates of median OS and 1-, 2- and 3-year OS probabilities.

We found four published articles that fit the research criteria $^{1,12-14}$ (Table 1). The baseline characteristics of patients who received azacitidine monotherapy in these trials are relatively comparable in terms of age, Eastern Cooperative Oncology Group Performance Status (ECOG 
Table 1 Summary of articles included

\begin{tabular}{|c|c|c|c|c|c|c|c|}
\hline Paper & $\begin{array}{l}\text { Treatment } \\
\text { Dosing and treatment schedule } \\
\text { Median number of cycles }\end{array}$ & $N$ & $\begin{array}{l}\text { Age } \\
\text { Median } \\
\text { (range) }\end{array}$ & ECOG PS & IPSS & $\begin{array}{l}\text { Median } \\
\text { Time of follow-up in } \\
\text { months (range) }\end{array}$ & $\begin{array}{l}\text { Median } \\
\text { OS in months } \\
(95 \% \mathrm{Cl})\end{array}$ \\
\hline $\begin{array}{l}\text { Fenaux et al. } \\
(\text { AZA-001) }\end{array}$ & $\begin{array}{l}\text { Azacitidine } \\
75 \mathrm{mg} / \mathrm{m}^{2} \text { for } 7 \text { days every } 28 \text { days } \\
4 \text { cycles (IQR } 4-15 \text { ) }\end{array}$ & 179 & $69(42-83)$ & $\begin{array}{l}0: 44 \% \\
1: 48 \% \\
2: 7 \% \\
\text { NA: } 1 \%\end{array}$ & $\begin{array}{l}\text { Low: } 0 \% \\
\text { Int-1: } 3 \% \\
\text { Int-2: } 43 \% \\
\text { High: } 46 \%\end{array}$ & $\begin{array}{l}21.1 \\
(I Q R \text { 15-27) }\end{array}$ & $\begin{array}{l}24.5 \\
(9.9-\text { not } \\
\text { reached) }\end{array}$ \\
\hline $\begin{array}{l}\text { Garcia-Manero } \\
\text { et al. }{ }^{12}\end{array}$ & $\begin{array}{l}\text { Azacitidine }+ \text { Placebo } \\
75 \mathrm{mg} / \mathrm{m}^{2} \text { for } 7 \text { days every } 28 \text { days } \\
\text { Median number of cycles not shown: } \\
69 \% \text { received } \geq 5 \text { cycles }\end{array}$ & 51 & $69(43-83)$ & $\begin{array}{l}0: 31 \% \\
\text { 1: } 61 \% \\
\text { 2: } 0 \% \\
\text { A: } 8 \%\end{array}$ & $\begin{array}{l}\text { Low: } 0 \% \\
\text { Int-1: } 0 \% \\
\text { Int-2: } 67 \% \\
\text { High: } 33 \%\end{array}$ & 15 & 19 \\
\hline $\begin{array}{l}\text { Sekeres et al. } \\
13\end{array}$ & $\begin{array}{l}\text { Azacitidine } \\
75 \mathrm{mg} / \mathrm{m}^{2} \text { for } 7 \text { days every } 28 \text { days } \\
6 \text { cycles }\end{array}$ & 92 & $69(42-88)$ & $\begin{array}{l}0: 31 \% \\
\text { 1: } 59 \% \\
\text { 2: } 10 \% \\
\text { NA: } 0 \%\end{array}$ & $\begin{array}{l}\text { Low: } 3 \% \\
\text { Int-1: } 28 \% \\
\text { Int-2: } 45 \% \\
\text { High: } 23 \%\end{array}$ & $23(1-43)$ & 15 \\
\hline Silverman et al. ${ }^{14}$ & $\begin{array}{l}\text { Azacitidine } \\
75 \mathrm{mg} / \mathrm{m}^{2} \text { for } 7 \text { days every } 28 \text { days } \\
\text { Median number of cycles not shown, } \\
\text { response was assessed after the fourth } \\
\text { cycle }\end{array}$ & 99 & $69(31-92)$ & $\begin{array}{l}\text { Not } \\
\text { provided }\end{array}$ & $\begin{array}{l}\text { Low: } 2 \% \\
\text { Int-1: } 26 \% \\
\text { Int-2: } 11 \% \\
\text { High: } 9 \%\end{array}$ & Not provided & $20(16-26)$ \\
\hline
\end{tabular}

ECOG PS Eastern Cooperative Oncology Group Performance Status, IPSS International Prognostic Scoring System, NA not available, IQR interquartile range

PS), and distribution of risk status as reflected by the International Prognostic Scoring System (IPSS). When $\mathrm{KM}$ curves for the azacitidine arm of each of the four articles were pooled (Figs. 1a, b), median OS was 19.2 months (95\% CI 16.9-21.8 months). KM estimates of OS for pooled data at 1 year was $65.4 \%$ (95\% CI $60.8-70.3 \%)$, at 2 years was $42.4 \%$ (95\% CI $37.3-48.3 \%)$, and at 3 years was $33.6 \%$ (95\% CI $27.6-40.8 \%$ ).

In conclusion, pooled data from clinical trials with azacitidine monotherapy arms further support the reallife observation that the median OS of 24.5 months with azacitidine in AZA-001 trial reflects a substantial unexplained over-performance of azacitidine that is not related to the selective process of enrollment in clinical trials. A limitation of the study is that the data were pooled from different trials, which included disparate patient populations and used slightly different study designs.

One commonly cited reason for the underperformance of azacitidine compared with AZA-001 is the potential suboptimal use of azacitidine with regard to the administration schedule and persistence of therapy after a response is achieved ${ }^{2}$. Indeed, many community and some academic practices use alternative administration schedules to avoid weekend administration as demonstrated in the AVIDA registry study in which only $15 \%$ of MDS patients received azacitidine on the 7-day continuous administration schedule used in AZA-001 ${ }^{15}$. However, both the French compassionate use program ${ }^{5}$ and the
Spanish MDS registry study ${ }^{4}$ used the 7 -day consecutive schedule of azacitidine in most patients without approaching the OS reported in AZA-001. Even more, in the Spanish compassionate use program study ${ }^{7}$, there was no statistically significant difference in OS between patients receiving azacitidine on a 7-day consecutive schedule vs. on alternative schedules. The observed median OS in the other three randomized trials included in our analysis argue against an effect of the schedule (Table 1).

Due to different dynamics of response achievement in comparison with standard chemotherapy and the rarity of MDS, azacitidine is sometimes discontinued prematurely in patients before a minimum period of 6 months (which is recommended on the basis that $87 \%$ of patients who responded in AZA-001 achieved their response within the first 6 cycles) has passed ${ }^{2}$. For example, in the AVIDA registry patients received only a median of four cycles of azacitidine ${ }^{15}$ and in the Groupe Français des Myélodysplasies compassionate use program $17 \%$ of patients received $<4$ cycles of azacitidine ${ }^{5}$. However, in the SWOGS1117 study patients received a median of six cycles of azacitidine ${ }^{13}$ and in the phase II trial by GarciaManero et al. $69 \%$ of patients received $\geq 5$ cycles of azacitidine $^{12}$, still patients in both studies had significantly shorter OS compared with patients in the AZA-001 trial (Table 1).

Based on our study and a growing body of evidence, a median OS of 19 months (based on trial data of selected 


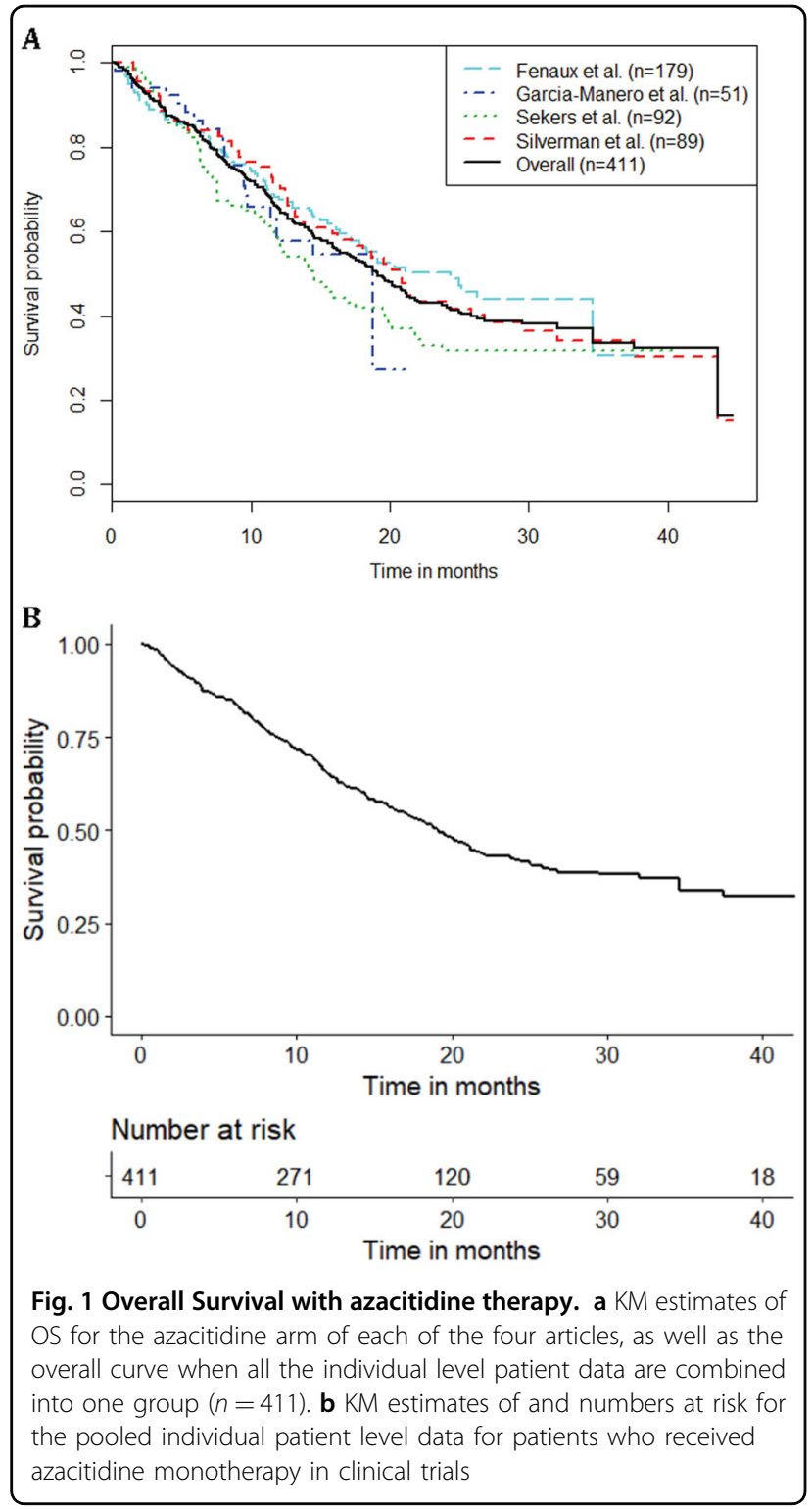

patients) and 13-16 months (based on real-life analyses) might be more realistic estimates for most patients with HR-MDS using azacitidine. Although individual patients have exceptionally long-lasting responses with azacitidine, such responses are uncommon. Indeed, a recent analysis from SEER Medicare data showed that the 5-year OS probability for patients with RAEB who were treated with hypomethylating agents was a dismal $4 \% \quad(95 \%$ CI $2-6 \%)^{16}$. Additionally, it is important to keep in mind that only about half of HR-MDS patients treated with hypomethylating agents experience a response, and there are no reliable methods to predict whether patients will benefit from this therapy ${ }^{2}$. Even if patients are initially responding to hypomethylating agent therapy, once therapy fails, the median OS is only $4-6$ months and no current therapy has been shown to add a survival benefit in that setting ${ }^{2}$. In this context, our analysis adds to the exiting evidence of the suboptimal performance of azacitidine and provides a rationale to strongly consider firstline enrollment into clinical trials or transplantation for HR-MDS patients rather than defaulting to the routine use of "standard-of-care" azacitidine monotherapy ${ }^{2}$.

\section{Acknowledgements}

This research was partly funded by the Dennis Cooper Hematology Young Investigator Award. The authors acknowledge the Frederick A. DeLuca Foundation for financial support.

\section{Author details \\ ${ }^{1}$ Yale University and Yale Cancer Center, New Haven, CT, USA. ${ }^{2}$ Yale Cancer Outcomes Public Policy, and Effectiveness Research (COPPER) Center, New Haven, CT, USA. ${ }^{3}$ Department of Biostatistics, Yale School of Public Health, New Haven, CT, USA. ${ }^{4}$ Department of Chronic Diseases, Yale School of Public Health, Yale University, New Haven, CT, USA. ${ }^{5}$ Department of Health Policy and Management, School of Public Health, Yale University, New Haven, CT, USA}

\section{Authors' contributions}

Dr. M.S. and Dr. A.M.Z. analyzed the results and wrote the manuscript. Dr. M. $\mathrm{DeV}$. conducted the analyses. All authors designed the study and participated in data analysis and interpretation. All authors edited and approved the final version of the manuscript.

\section{Conflict of interest}

Dr. M.S., Dr. M.DeV., Dr. S.G. and Dr. R.W. declare that they have no conflict of interest. Dr. N.P. consulted for CTI biopharma, Alexion, Ariad, Pfizer and Incyte. Dr. S.H. consulted for Janssen and Celgene and received honoraria from Pharmacyclics. Dr. X.M. consulted for Celgene and Incyte. Dr. S.D.G. consulted and received research funding from Celgene. Dr. A.J.D. received research funding from Celgene. Dr. A.M.Z. consulted for Celgene, Ariad, Gilead, Incyte and Pfizer and served as a speaker for Ariad. These sources of support were not used for any portion of the current study.

\section{Publisher's note}

Springer Nature remains neutral with regard to jurisdictional claims in published maps and institutional affiliations.

Received: 13 March 2018 Revised: 21 March 2018 Accepted: 3 April 2018 Published online: 11 June 2018

\section{References}

1. Fenaux, P. et al. Efficacy of azacitidine compared with that of conventional care regimens in the treatment of higher-risk myelodysplastic syndromes: a randomised, open-label, phase III study. Lancet Oncol. 10, 223-232 (2009).

2. Zeidan, A. M. et al. A call for action: increasing enrollment of untreated patients with higher-risk myelodysplastic syndromes in first-line clinical trials. Cancer 123, 3662-3672 (2017).

3. Zeidan, A. M. et al. Comparison of risk stratification tools in predicting outcomes of patients with higher-risk myelodysplastic syndromes treated with azanucleosides. Leukemia 30, 649-657 (2016).

4. Bernal, T. et al. Effectiveness of azacitidine in unselected high-risk myelodysplastic syndromes: results from the Spanish registry. Leukemia 29, 1875-1881 (2015).

5. Itzykson, R. et al. Prognostic factors for response and overall survival in 282 patients with higher-risk myelodysplastic syndromes treated with azacitidine. Blood 117, 403-411 (2011).

6. van der Helm, L. H. et al. Platelet doubling after the first azacitidine cycle is a promising predictor for response in myelodysplastic syndromes (MDS), chronic myelomonocytic leukaemia (CMML) and acute myeloid leukaemia (AML) patients in the Dutch azacitidine compassionate named patient programme. Br. J. Haematol. 155, 599-606 (2011). 
7. Garcia-Delgado, R. et al. Effectiveness and safety of different azacitidine dosage regimens in patients with myelodysplastic syndromes or acute myeloid leukemia. Leuk. Res. 38, 744-750 (2014).

8. Gangat, N. et al. Survival trends in primary myelodysplastic syndromes: comparative analysis of 1000 patients by year of diagnosis and treatment. Blood Cancer J. 6, e414 (2016).

9. Zeidan, A. M. et al. Comparative clinical effectiveness of azacitidine versus decitabine in older patients with myelodysplastic syndromes. Br. J. Haematol. 175, 829-840 (2016).

10. Zeidan, A. M. et al. Modest improvement in survival of patients with refractory anemia with excess blasts in the hypomethylating agents era in the United States. Leuk. Lymphoma 58, 982-985 (2017).

11. Guyot, P., Ades, A. E., Ouwens, M. J. \& Welton, N. J. Enhanced secondary analysis of survival data: reconstructing the data from published Kaplan-Meier survival curves. Bmc. Med. Res. Methodol. 12, 9 (2012).
12. Garcia-Manero, G. et al. Phase 2, randomized, double-blind study of pracinostat in combination with azacitidine in patients with untreated, higher-risk myelodysplastic syndromes. Cancer 123, 994-1002 (2017).

13. Sekeres, M. A. et al. Randomized phase II study of azacitidine alone or in combination with lenalidomide or with vorinostat in higher-risk myelodysplastic syndromes and chronic myelomonocytic leukemia: North American Intergroup Study SWOG S1117. J. Clin. Oncol. 35, 2745-2753 (2017).

14. Silverman, L. R. et al. Randomized controlled trial of azacitidine in patients with the myelodysplastic syndrome: a study of the cancer and leukemia group B. J. Clin. Oncol. 20, 2429-2440 (2002).

15. Grinblatt, D. L. et al. Patients with myelodysplastic syndromes treated with azacitidine in clinical practice: the AVIDA registry. Leuk. Lymphoma 56, 887-895 (2015)

16. Zeidan, AM. et al. Long-term survival of older patients with MDS treated with HMA therapy without subsequent stem cell transplantation. Blood 131, 818-821 (2018) 